\title{
Pectin Ultra-degradation Decreases the Force Required to Detach Ripe Fruit from the Calyx in Tabasco Pepper
}

\author{
Ramón A. Arancibia ${ }^{1}$ and Carl E. Motsenbocker ${ }^{2}$ \\ Department of Horticulture, Louisiana State University Agricultural Center, 137 J.C. Miller Hall, \\ Baton Rouge, LA 70803
}

\begin{abstract}
AdDitional INDEX wORDS. depolymerization, galacturonic acid, size-exclusion chromatography, deciduous fruit, mechanical harvest

ABSTRaCt. Pectin metabolism was analyzed in tabasco pepper (Capsicum frutescens L.) to determine the metabolic process associated with the ease of fruit detachment from the calyx. The ease of fruit detachment (deciduous fruit) is a desirable trait in peppers that facilitates mechanical harvest. Two genotypes that differ in the fruit detachment force were used: 'Easy Pick' (EZ), which requires a low force, and 'Hard Pick' (HP), which requires higher force. Pectin dissolution in water from fresh-ripe EZ tissue was 20 times higher than from HP tissue. EDTA-soluble uronide from inactivated EZ cell wall, however, was only 1.8 times higher. Pectin dissolution was inversely correlated to the fruit detachment force and followed a sigmoidal curve during fruit ripening. Size-exclusion chromatography of EDTA-soluble polyuronides indicated that pectin was degraded in ripe fruit tissue from both genotypes. The degree of depolymerization, however, was more extensive in EZ fruit. Consequently, the ease of fruit detachment was attributed to pectin ultra-degradation. Total pectin content in dry tissue and ethanol/acetone-extracted cell wall was similar in both genotypes. Pectin content in dry tissue was maintained throughout ripening, while extracted cell wall pectin increased slightly. In contrast, the degree of pectin esterification of extracted cell wall decreased only in ripe EZ fruit. These results suggest that pectin de-esterification may have a role in the enhanced pectin depolymerization and consequently in the ease of fruit detachment of the EZ genotype.
\end{abstract}

The fruit of most cultivated peppers (Capsicum spp. L.) adheres tightly to the calyx when ripe and the pedicel remains attached to the fruit when harvested (Motsenbocker, 1996; Smith, 1951). This is a concern in processing for pepper sauce because woody pedicel and green calyx introduced into the mash impart off-color and lower the sauce quality. Consequently, to comply with the low tolerance for green-woody tissue, fruits are de-stemmed, affecting the harvest and postharvest cost. Although most peppers are hand harvested, cultivars with the deciduous fruit trait (fruit that separates easily from the calyx) have been selected to facilitate mechanical harvest (Bosland and Iglesias, 1992; Davis, 1980; Motsenbocker, 1996). The metabolic process conducing to the ease of fruit separation, however, is not well understood, and needs to be addressed in order to develop cultivars suitable for mechanical harvest and processing.

The ease of fruit detachment from the calyx in peppers was reported to be inherited as a single dominant gene (Smith, 1951). This characteristic was later designated "soft-flesh" since it is the consequence of fruit tissue disintegration. A similar phenotypic characteristic has been described in tomato (Lycopersicon esculentum Mill.) (Rick and Sawant, 1955) and peach [Prunus persica (L.) Batsch] (Lester et al., 1996). Histological studies with tabasco pepper (C.frutescens) detachment zone indicated that the

Received for publication 3 Mar. 2004. Accepted for publication 20 May 2004. Approved for publication by the director of the Louisiana Agricultural Experiment Station as manuscript no. 04-34-0106. This paper is a portion of a dissertation submitted by Ramón A. Arancibia. Mention of trademark, proprietary product, or vendor does not imply endorsement of the product named nor criticism of similar ones not named.

${ }^{1}$ Former Graduate Student.

${ }^{2}$ Associate Professor.

Developmental Physiology. peripheral parenchyma cells of easy detaching fruit stretched and the intercellular space enlarged as less and less middle lamella was bound between adjacent cells (Sundberg et al., 2003). This process was similar to that of cell wall degradation and cell separation at the fruit-pedicel abscission zone in peach which was attributed to polygalacturonase (PG) and endo- $\beta-1,4$-glucanase activity (Zanchin et al., 1993). These results suggest that the ease of fruit detachment in ripe tabasco pepper is associated with extensive cell wall degradation and PG-mediated pectin degradation appears to be a factor (Rao and Paran, 2003).

Pectin architecture and metabolism play a role in the integrity of plant cell wall (Brummell and Harpster, 2001) and in the texture of fruits and vegetables (Jarvis, 1984). Pectin is composed of alternate branched blocks of methyl-esterified polyuronides with unbranched blocks of varying degrees of esterification (Jarvis, 1984). The unbranched blocks aggregate through $\mathrm{Ca}^{2+}$ bridges between de-esterified carboxylic groups of adjacent polymers keeping the cell wall matrix coherent and maintaining cell to cell adhesion. Pectin degradation in ripening tomato fruit has been associated with a progressive reduction of the uronide molecular size (depolymerization) which was attributed to PG action (DellaPenna et al., 1990; Huber, 1983). In addition, studies with isolated cell wall showed that pectin degradation and dissolution by PG is more effective in de-esterified cell wall (Pressey and Avants, 1982). PG activity is present in ripe tomato (Brummell and Harpster, 2001) and pepper (C. аппиит) (Sethu et al., 1996) and it has been associated with fruit softening. PG is also a candidate for the ease of fruit detachment in pepper (Rao and Paran, 2003).

The objective of this study was to investigate the role of pectin degradation in the ease of fruit detachment from the calyx in tabasco pepper. Pectin depolymerization and dissolution can disrupt cell wall structure which could lead to cell separation 
at the fruit detachment zone. The level of pectin degradation in relation to fruit detachment force and the role of pectin de-esterification is discussed.

\section{Materials and Methods}

Plant material. Tabasco pepper 'Easy Pick' (EZ), which requires a low force to separate red-mature fruit from the calyx, and 'Hard Pick' (HP), which requires a higher force, were used in this study. Plants were grown individually in 12-L pots under greenhouse conditions at the Louisiana State Univ. Agricultural Center as described previously (Motsenbocker, 1996). Plants were randomly distributed in the greenhouse with each plant considered an experimental unit. Assays were conducted with fruit from one plant and repeated at least three times with material from other plants. Four to six fruits of different ripening stages and without signs of dehydration were harvested and the fruit external color (hue) was determined by colorimetric analysis in a Minolta CM3500d spectrophotometer (Minolta, Tokyo). In addition, the fruit detachment force in Newton $(\mathrm{N})$ required to separate fruit from the calyx was determined for each fruit using a Chatillon CE Digital Force Gauge DFIS 10 (John Chatillon \& Sons, Greensboro, N.C.) as described by Motsenbocker (1996).

TISSUE AND CELL WALL PREPARATION. After removing the pedicel, a 3 -mm-thick disk (20 to $30 \mathrm{mg}$ ) from the fruit detachment zone was excised. The disk was assayed fresh, or it was frozen in liquid nitrogen and freeze-dried. To extract cell wall, freeze-dried tissue was ground in $0.5 \mathrm{~mL}$ of $100 \%$ ethanol, heat-inactivated at $90{ }^{\circ} \mathrm{C}$ for $20 \mathrm{~min}$, and centrifuged at $16000 \mathrm{~g}_{\mathrm{n}}$ for $5 \mathrm{~min}$ in a Eppendorf $5415 \mathrm{C}$ centrifuge (Eppendorf AG, Hamburg, Germany). The pellet was rinsed three times by cycles of $0.5 \mathrm{~mL}$ acetone and centrifugation, and then air-dried. Cell wall samples were kept in vacuum at room temperature until used.

Pectin dissolution. The excised fresh tissue was immersed in $600 \mu \mathrm{L}$ water for $10 \mathrm{~min}$ and the soluble pectin that diffused into solution was determined as uronic acid (UA) equivalents by the method of Blumenkrantz and Asboe-Hansen (1973) using m-hydroxybiphenyl (Sigma Chemical Co., St Louis) as chromogenic reagent and polygalacturonic acid (Sigma Chemical Co.) as standard. Similarly, cell wall chelator-soluble UA was quantified from a suspension of cell wall $\left(5 \mathrm{mg} \cdot \mathrm{mL}^{-1}\right)$ in extraction buffer (50 mm Na acetate, 40 mm EDTA, pH 4.5) after $1 \mathrm{~h}$. The correlation between fruit detachment force and soluble UA was analyzed.

Total URONIDE CONTENT. Total uronide was extracted from freeze-dried tissue and cell wall ( $5 \mathrm{mg}$ ) by digestion and dissolution in $2 \mathrm{mLH}_{2} \mathrm{SO}_{4}$ as described by Ahmed and Labavitch (1977). The solution was then diluted with water to a suitable concentration and tested for UA content by the m-hydroxybiphenyl method (Blumenkrantz and Asboe-Hansen, 1973).

Pectin depolymerization. The degree of depolymerization of EDTA-soluble pectin extracted from cell wall was determined by size-exclusion chromatography following the method of DellaPenna et al. (1990) with some modifications. The cell wall sample was suspended in extraction buffer $(50 \mathrm{~mm} \mathrm{Na}$ acetate, $40 \mathrm{~mm}$ EDTA, $\mathrm{pH} 4.5$ ) overnight at $4{ }^{\circ} \mathrm{C}$ and diluted to give a uronide concentration of $0.5 \mathrm{mg} \cdot \mathrm{mL}^{-1}$. The sample was centrifuged and $1 \mathrm{~mL}$ of the supernatant was assayed through a Sepharose CL4B (Sigma Chemical Co.) column $(30 \times 1.5 \mathrm{~cm})$ equilibrated with elution buffer (100 mm Na acetate, 20 mm EDTA, pH 6.5). Galacturonic acid (Sigma Chemical Co.) $\left(0.5 \mathrm{mg} \cdot \mathrm{mL}^{-1}\right)$ was used as the monomer standard. The elution rate was $0.4 \mathrm{~mL} \cdot \mathrm{min}^{-1}$ and $2 \mathrm{~mL}$ fractions were collected. The UA content of each fraction was determined by the m-hydroxybiphenyl method (Blumenkrantz and Asboe-Hansen, 1973) and expressed as a percentage of recovery from the sample.

Degree of PECTIN ESTERIfiCation (DPE). Cell wall pectin was de-esterified by saponification to release the methyl groups as methanol (Wood and Siddiqui, 1971). The cell wall sample $(5 \mathrm{mg})$ was suspended in $600 \mu \mathrm{L}$ water and treated with $300 \mu \mathrm{L}$ $1.5 \mathrm{~N} \mathrm{NaOH}$ at room temperature for $1 \mathrm{~h}$. The suspension was chilled on ice, acidified with $300 \mu \mathrm{L}$ of cold $6 \mathrm{~N} \mathrm{H}_{2} \mathrm{SO}_{4}$ and centrifuged to precipitate the solid cell wall material and separate the liquid phase containing the released methanol in solution. The methanol molar content was determined chemically by the pentane-2,4-dione (Sigma Chemical Co.) method as described by Wood and Siddiqui (1971). Uronide content was determined as described above (Ahmed and Labavitch, 1977; Blumenkrantz and Asboe-Hansen, 1973) and the total molar content was estimated. The DPE was defined as the proportion of methanol to UA molar content in percent.

\section{Results}

Fruit color and RIPENING. Under greenhouse conditions, the ripening process of tabasco pepper from mature-green fruit until purple-red lasted between 13 and $16 \mathrm{~d}$. Fruit color changed progressively from green to yellow, orange, red, and culminated in purple-red. The fruit external color was used as ripening indicator and it was reported quantitatively by the hue value (angle in the CIELAB color space). A comparative description of fruit ripening stage based on color and the hue angle is as follows: immature- and mature-green (hue 102 to 95), yellow (hue 90 to 80 ), breaker stage (hue 75 to 65 ), orange (hue 60 to 50 ), redmature (hue 45 to 35 ), and purple-red fruit (hue $<35$ ). There was little or no change in the fruit external color when the fruit was left longer in the plant until signs of dehydration (overripe) were observed. The lowest fruit external color recorded was hue 28. In comparison, the red painted stick used as a commercial harvest index for tabasco peppers has hue 34 .

Fruit Detachment FORCE. The force required to separate ripe fruit from the calyx was different between the EZ and the HP tabasco genotypes as shown in Fig. 1. In the EZ genotype, the changes in fruit detachment force during ripening (between hue 102 and hue 30) followed a reverse sigmoidal curve with three phases (Fig. 1A). In phase I, fruit detachment force ranged between 17 and $26 \mathrm{~N}$ as fruit color changed from hue 102 to hue 52. In phase II, fruit detachment force dropped to $3 \mathrm{~N}$ as the hue value decreased to 48 . In phase III, the fruit detachment force remained low until the end of the ripening process and fruit color changed from hue 48 to hue 30 . In contrast, the pattern of fruit detachment force in the HP genotype was comprised of two phases (Fig. 1B). In phase I, fruit detachment force ranged between 18 and $27 \mathrm{~N}$ until hue 45, and then in phase II the fruit detachment force decreased to $\approx 10 \mathrm{~N}$ when fruit color reached hue 30 . The curve phases were determined within the range hue 102 and hue 30 and with fruit without signs of shriveling. When time (days) was the parameter used to represent ripening and time was extended to include overripe fruits, the fruit detachment force in the HP genotype followed a sigmoidal curve also (data not presented). Fruits of both genotypes softened when ripe, but EZ fruits were softer to the touch than HP fruits because the pericarp and placenta of EZ fruit were disintegrated almost 

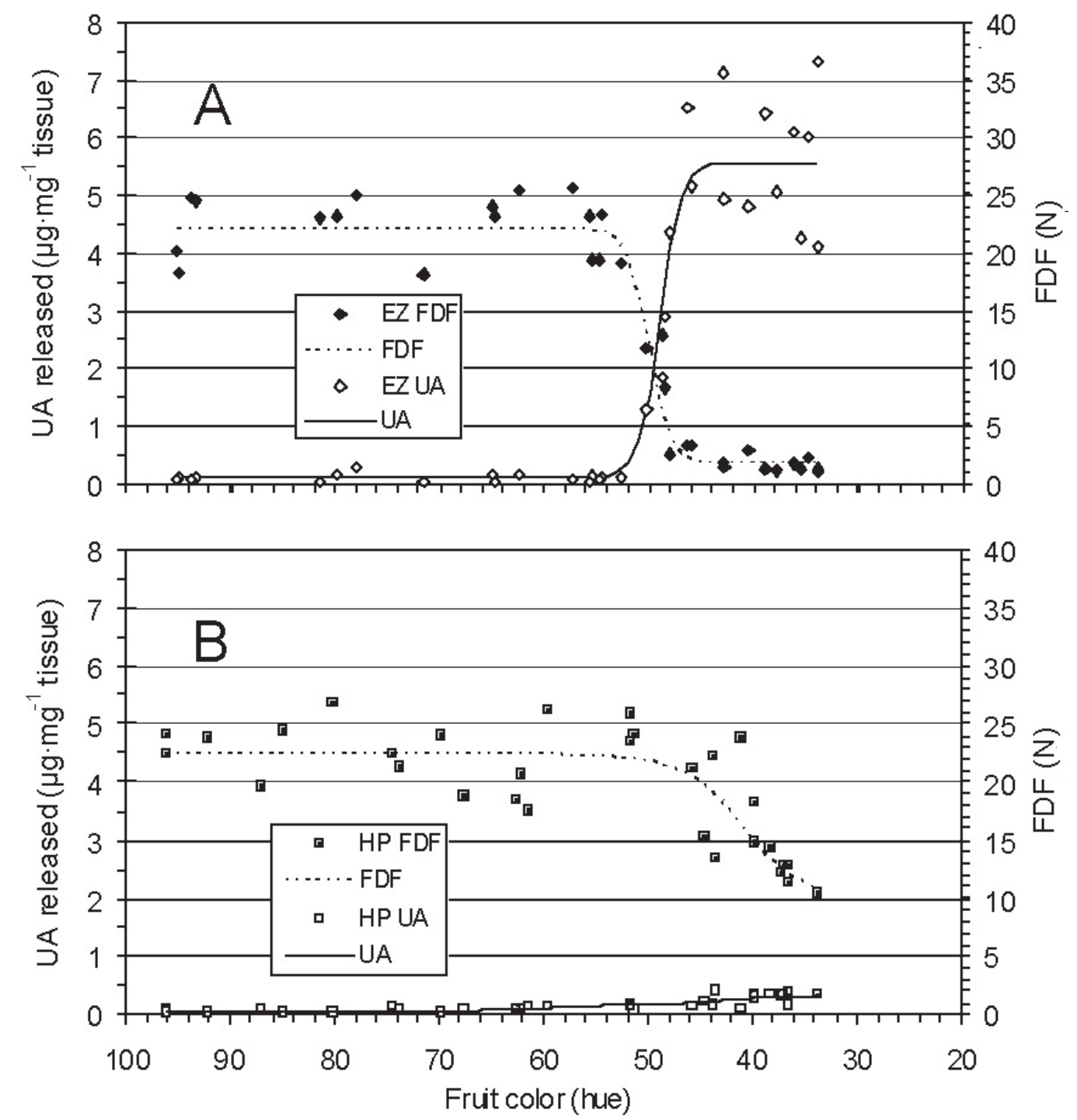

Fig. 1. Fruit detachment force (FDF) and water-soluble pectin [as uronic acid (UA)] released from tabasco pepper fruit detachment zones during ripening. (A) 'Easy Pick' (EZ) and (B) 'Hard Pick' (HP) genotypes. Fruit ripening is represented by the fruit external color (hue 100 corresponds to immature-green and hue 30 to purple-red). Coefficient of determination in A: $r^{2}=0.95$ (dash line) and $r^{2}=0.93$ (solid line), and in B: $r^{2}=0.64$ (dash line) and $r^{2}=0.70$ (solid line).

completely. Measuring the shear force in tabasco pepper fruit was not reliable to determine fruit softening because of the seed content (data not presented).

Pectin dissolution. The level of soluble uronide in fresh fruit tissue increased during ripening in both genotypes, but it was 20 times higher in ripe (hue <50) EZ fruit than in ripe HP fruit (Fig. 1). The changes in soluble UA coincided with the changes in fruit detachment force for each genotype. In the initial ripening stages (hue $>52$ ), soluble UA was very low or undetected and the fruit detachment force was high in both genotypes (phase I). Between hue 52 and hue 48, soluble UA in EZ fruit increased rapidly as fruit detachment force dropped (phase II). Then in phase III, soluble UA in EZ fruit remained high (average of $5.81 \mu \mathrm{g} \cdot \mathrm{mg}^{-1}$ fresh tissue) and fruit detachment force remained low until hue 30. In contrast, water soluble UA in HP fruit increased slightly in phase II (hue $<45$ ) reaching a maximum of $0.41 \mu \mathrm{g} \cdot \mathrm{mg}^{-1}$ fresh tissue. Correlation analysis indicated that pectin dissolution from the detachment area is well associated $(r=-0.92)$ with fruit detachment force which implies that pectin degradation in vivo is associated with the ease of fruit separation from the calyx.
The level of EDTA soluble uronide during fruit ripening for both genotypes is shown in Fig. 2. In the early ripening stages up to hue 53, soluble UA was low in both tabasco genotypes. EDTA-soluble UA increased, thereafter, reaching an average of 54 and $97 \mu \mathrm{g} \cdot \mathrm{mg}^{-1}$ cell wall in HP and EZ fruit, respectively, or 1.8 times higher in EZ than HP cell wall. Chelator soluble UA from cell wall was also associated $(r=-0.84)$ with fruit detachment force throughout ripening.

URONIDE CONTENT. Total uronide content in freeze-dried tissue and cell wall was analyzed for differences between both tabasco genotypes. Pectin content remained the same in both tabasco genotypes throughout ripening when extracted from freeze-dried tissue, and ranged between 78 and $104 \mu \mathrm{g} \cdot \mathrm{mg}^{-1}$ dried tissue with an average of $88 \mu \mathrm{g} \cdot \mathrm{mg}^{-1}$ dried tissue. Total uronide content in extracted cell wall during fruit ripening is shown in Fig. 2. UA content in cell wall was the same in both genotypes, but increased slightly as fruit ripened. Ethanol/acetone extraction of cell wall increased the proportion of pectin in comparison to freeze-dried tissue. Ethanol soluble sugars and acetone soluble lipids may account for this difference. 


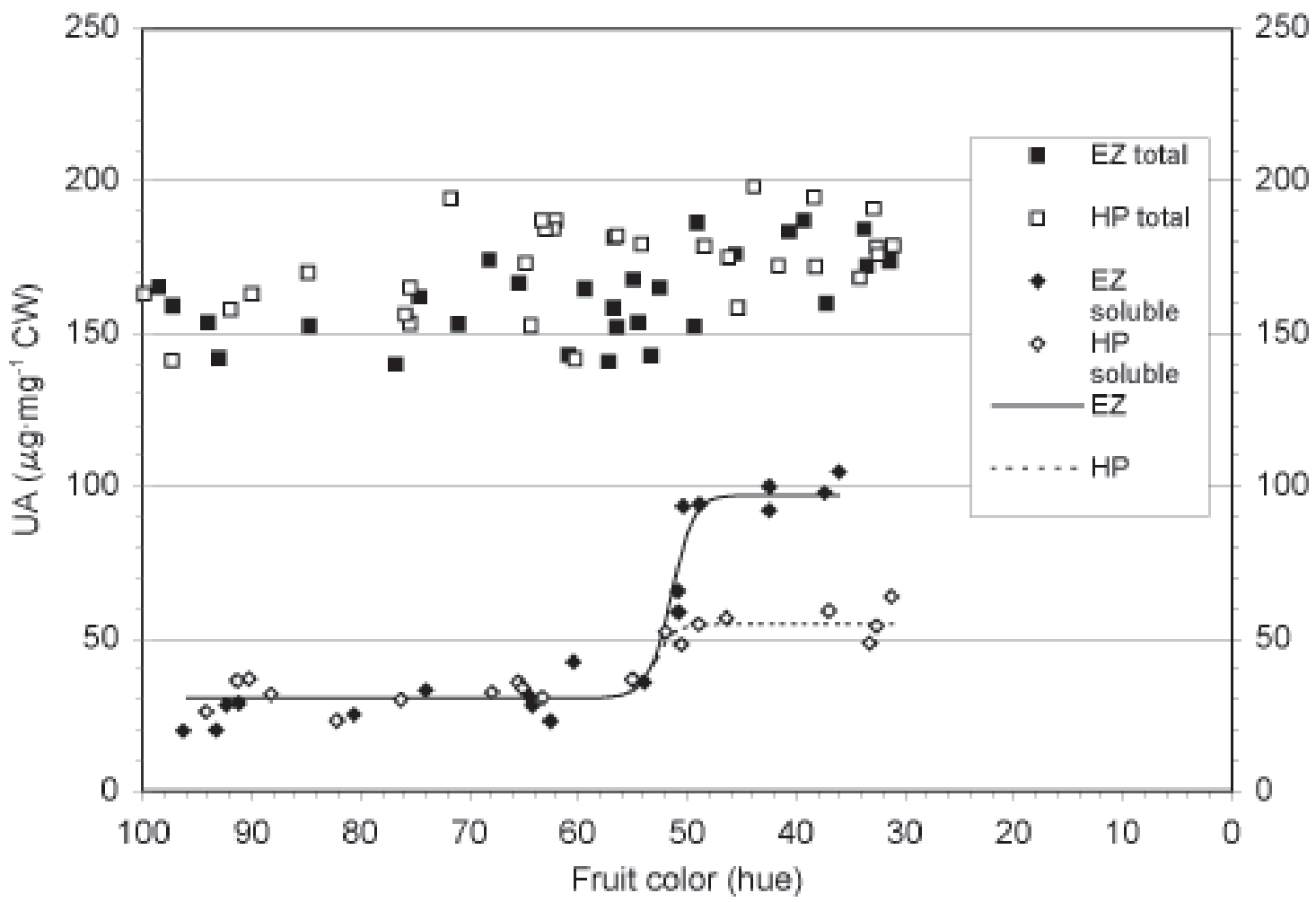

Fig. 2. Total and EDTA-soluble pectin [as uronic acid (UA)] in tabasco pepper cell wall (CW) during fruit ripening. Cell wall was extracted from 'Easy Pick' (EZ) and 'Hard Pick' (HP) fruit detachment zones. Fruit ripening is represented by the fruit external color (hue 100 corresponds to immature-green and hue 30 to purple-red). Coefficient of determination: $r^{2}=0.95$ (solid line) and $r^{2}=0.87$ (dash line).

Pectin depolymerization. The effect of PG activity in vivo was evaluated by the degree of pectin degradation determined by molecular size-exclusion chromatography. The molecular size profiles of EDTA-soluble polyuronide extracted from cell wall at two ripening stages are shown in Fig. 3. The elution profile of mature-green fruit (hue 94 and 97 for EZ and HP, respectively) was the same in both genotypes (Fig. 3A). Uronide polymers of large molecular size constitute the highest proportion of EDTAsoluble pectin that eluted first in the void volume followed by a tail of polyuronide of decreasing molecular size that extends up to the end of the separation range. In contrast, the elution profile of red-mature tissue was different between the genotypes (Fig. 3B). The elution profile of uronide from ripe (hue 40) EZ cell wall shows an almost complete downshift of the uronide molecular size to oligomers of a few galacturonic acid residues as a consequence of extensive depolymerization. In the case of ripe (hue 44) HP cell wall, the elution profile shows that uronide was distributed throughout a wide range of large to medium size UA polymers. This indicates that the degree of pectin depolymerization was less extensive than in the EZ genotype. This assay was performed also with heat inactivated freeze-dried tissue of similar ripening stages and the results were the same (data not presented). Higher pectin dissolution in the EZ line (Figs. 1 and 2), therefore, may be associated with extensive pectin depolymerization.

DEGREE OF PECTIN ESTERIFICATION. The association of the DPE with pectin degradation in vivo and therefore with the ease of fruit detachment was evaluated. The DPE in cell wall extracted from fruit detachment zones throughout fruit ripening is shown in Fig. 4. In the early ripening stages (hue $>60$ ), DPE was the same in both genotypes ranging between $55 \%$ and $78 \%$. As fruit ripened, DPE in HP fruit stayed within the same range until the end of the ripening process. In contrast, the DPE in EZ fruit decreased after hue 52 down to $43 \%$ when fruit color reached hue 30. DPE was correlated $(r=0.78)$ also with the fruit detachment force indicating that pectinesterase may have a role in the ease of fruit detachment. Lower DPE indicates increased substrate available for PG action, which may explain the extensive pectin depolymerization in the EZ genotype.

\section{Discussion}

The ease of pepper fruit detachment from the calyx when ripe is characterized by a dramatic decrease in fruit detachment force which results in clean fruit separation during harvest while the pedicel remains on the plant (Motsenbocker, 1996; Smith, 1951). This characteristic may not always be a desirable trait, as modern cultivars have been bred for larger and heavier fruit tightly attached to the plant. A similar phenomenon, however, was reported in tomato (Rick and Sawant, 1955) and appears to be equivalent to the melting/nonmelting flesh described in peach (Lester et al., 1996). The results of this study indicate that pepper fruit separation at the fruit-calyx junction is the consequence of pectin degradation intrinsic to fruit ripening instead of the formation of an abscission layer. This is supported by the lack of a distinct layer of cells identifiable as an abscission zone in the fruit-calyx junction of cayenne (C. annиum) (Gersch et al., 1998) and tabasco pepper (Sundberg et al., 2003). The difference in the force required to remove ripe fruit from the pedicel for EZ and HP tabasco pepper appears to depend on the degree of pectin degradation as indicated by solubility studies (Figs. 1 and 2). Pectin degradation and fruit detachment force reduction occurred in both genotypes. The earlier and pronounced fruit 

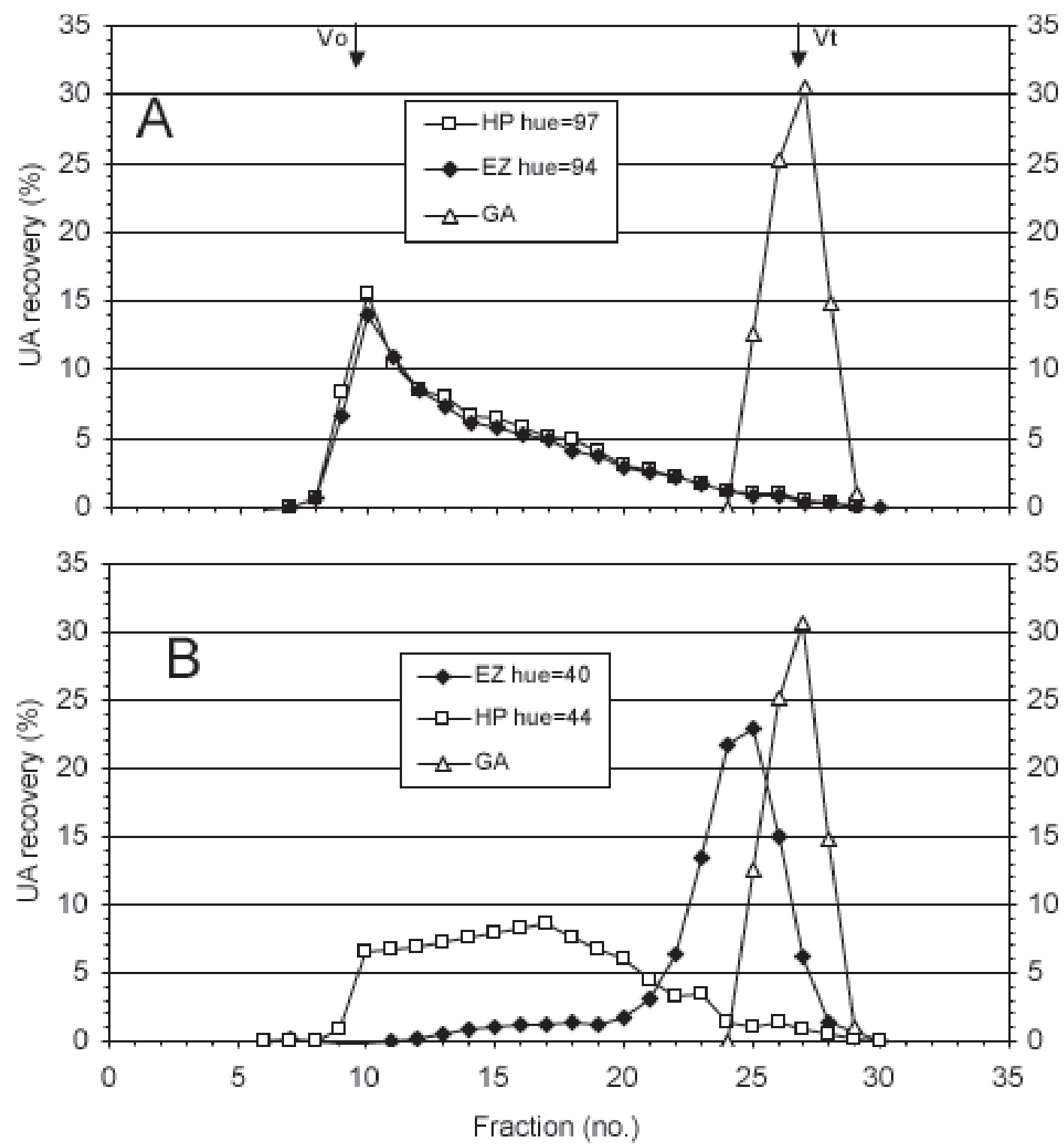

Fig. 3. Size-exclusion chromatography profile of EDTA-soluble polyuronide from 'Easy Pick' (EZ) and 'Hard Pick' (HP) tabasco pepper fruit detachment zone. EDTA-soluble polyuronide from mature-green fruit cell wall $(\mathbf{A})$ and red-mature fruit cell wall $(\mathbf{B})$ was fractionated in a Sepharose CL4B column $(30 \times 1.5 \mathrm{~cm})$. Arrows indicate void (Vo) and total (Vt) elution volumes. Uronide content [as uronic acid (UA)] in each $2 \mathrm{~mL}$ fraction is expressed as percentage of the total UA assayed. Galacturonic acid (GA) was used as monomer standard. Fruit ripening was determined by the fruit external color (hue).

detachment force drop in the EZ tabasco genotype (Fig. 1A), however, appears to be the result of pectin ultra-depolymerization [extensive depolymerization (Fig. 3B) into oligouronide of a few UAresidues (Huber and O'Donoghue, 1993)] that caused the fruit tissue to disintegrate. The ripening stage between hue 52 and hue 48 was the critical stage for the fruit detachment force decline (Fig. 1). Postharvest analysis of external fruit color indicated that this stage lasts between 10 and $15 \mathrm{~h}$ (data not presented). At this stage, pectin dissolution increased (Figs. 1 and 2) while DPE decreased (Fig. 4) in association with the fruit detachment force drop. Pectin ultra-degradation in EZ fruit detachment zones was consistent with reduced cell to cell adhesion found at the fruit-calyx junction of EZ tabasco pepper (Sundberg et al., 2003) and peach (Zanchin et al., 1993). In addition, these results support the relationship between the degree of PG-mediated pectin degradation and the level of fruit softening, and the association between the ease of fruit detachment and pectin ultra-degradation in ripe tabasco pepper.

Pectin metabolism during fruit ripening in tabasco pepper was characterized by increased soluble uronide (Figs. 1 and 2) and decreased polyuronide molecular size (Fig. 3), while total pectin content remained the same as determined in freeze-dried tissue or increased slightly as determined in extracted cell wall (Fig. 2). Pectin degradation by PG in tomato during fruit ripening exhibited these same characteristics, although the level of pectin dissolution and the degree of pectin depolymerization varied according to the methodology and variety (Brummell and Labavitch, 1997; DellaPenna et al., 1990; Huber, 1983; Watson et al., 1994). Chelator-soluble pectin extracted from cell wall is considered to be ionically bound and part of the cell wall structure (Jarvis, 1984). This appears not to be the case in tabasco pepper fruit since the profile of EDTA-soluble UA in extracted cell wall 


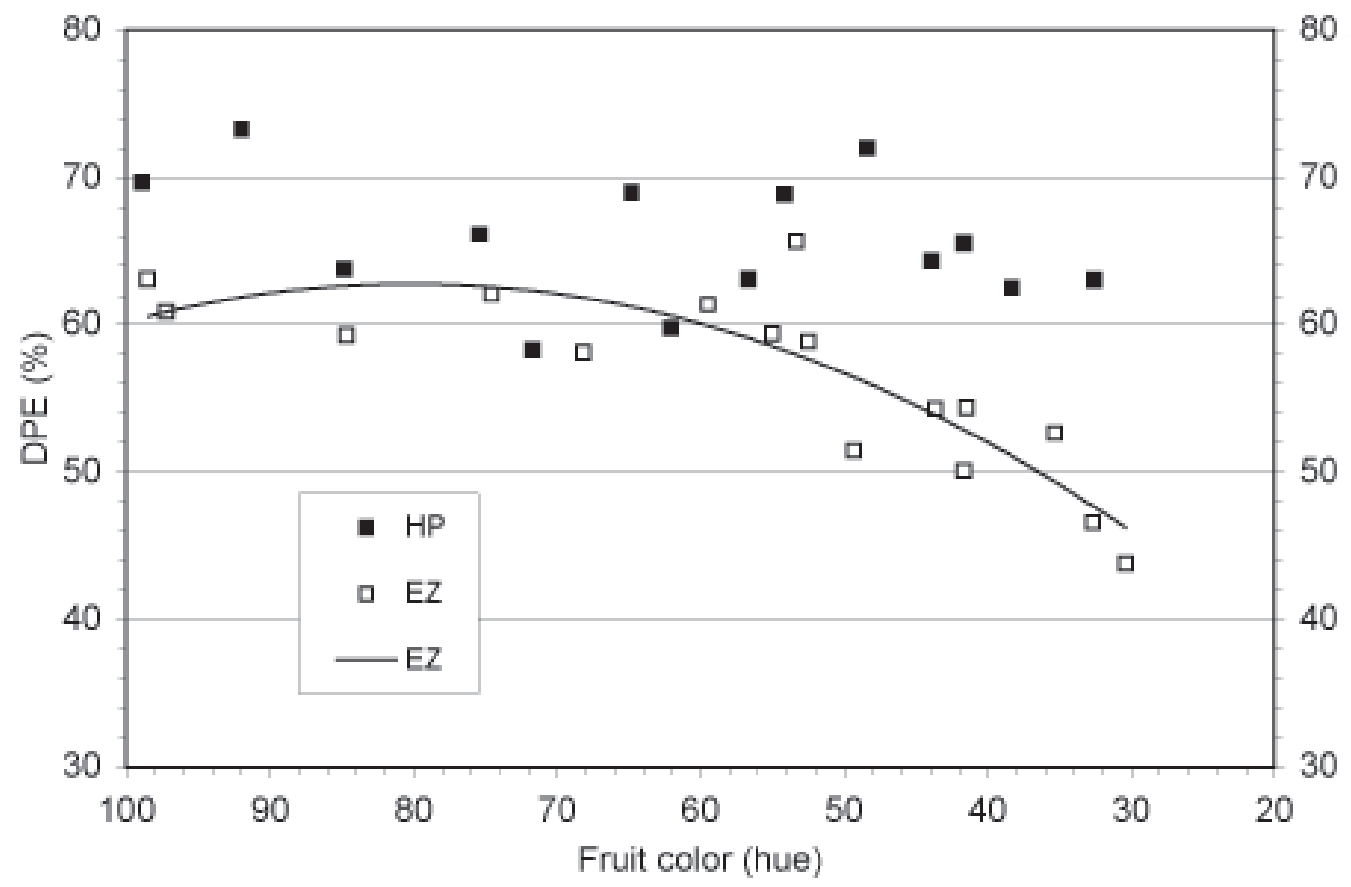

Fig. 4. Degree of pectin esterification (DPE) in fruit cell wall during ripening. Cell wall was extracted from tabasco pepper 'Easy Pick' (EZ) and 'Hard Pick' (HP) fruit detachment zones. The DPE was defined as the proportion (\%) of methanol to uronide molar content. Fruit ripening is represented by the fruit external color (hue 100 corresponds to immature-green and hue 30 to purple-red). Coefficient of determination: $r^{2}=0.69$ (solid line).

throughout ripening (Fig. 2) was similar to the profile of water soluble UA in cell wall from both genotypes (data not presented). The levels of EDTA-soluble UA(DellaPenna et al., 1990; Watson et al., 1994) and water-soluble UA (Gross and Wallner, 1979) reported in tomato were similar to the levels detected in tabasco pepper. Nevertheless, the difference in water-soluble uronide that diffused out from fresh detachment area was higher between ripe and unripe fruit, and also between EZ and HP ripe fruit (Fig. 1). Similar differences in water-soluble UA that diffused from tomato pericarp discs during fruit ripening were reported between normal and non-softening tomato lines (Koch and Nevins, 1990), although the soluble UA was extracted by centrifugation.

Pectin dissolution from fresh fruit tissue depends on the size of the uronide polymer. In contrast to galacturonic acid and UA oligomers, dissolution of larger pectin polymers is difficult because they are ionically bound and form part of the cell wall structure (Jarvis, 1984). In mature-green tabasco fruit, the size exclusion profile of EDTA-soluble uronide was the same for both genotypes (Fig. 3A) and it was indistinguishable from those reported for tomato (Brummell and Labavitch, 1997; DellaPenna et al., 1990; Huber and O'Donoghue, 1993). At this stage, large pectin polymers were tightly bound so they were not released from fresh tissue into water (Fig. 1), unless the cell wall structure was disrupted allowing some dissolution (Fig.2). In red-ripe HP tabasco fruit, there was a limited degree of pectin depolymerization that was comparable to levels found in ripe wild-type tomato (Brummell and Labavitch, 1997; DellaPenna et al., 1990; Huber and O’Donoghue, 1993). Pectin dissolution from fresh HP fruit at this stage increased slightly (Fig. 1B) indicating that most of the pectin was still ionically bound and maintaining the integrity of the cell wall structure. In contrast, pectin ultra-depolymerization detected in ripe fruit of the EZ genotype was similar to that found in ripe 'Hass' and 'Lula' avocado (Persea americana Mill.), in enzymatically active alcohol-insoluble solids from tomato after incubation (Huber and O'Donoghue, 1993), and in tomato paste (Brummell and Labavitch, 1997). Consistent with the reduced cell to cell adhesion in this genotype (Sundberg et al., 2003), highly degraded oligouronide no longer holds the cell wall structure intact leading to its disintegration. Consequently, oligouronide easily diffused out from fresh tissue (Fig. 1A). These results suggest that pectin ultra-degradation exhibited by the EZ genotype is the consequence of an enhanced PG activity in vivo not detected in HP fruit. Although PG appears to be a candidate for the soft flesh and ease of fruit detachment in tabasco pepper (Rao and Paran, 2003), pectin depolymerization was detected in both genotypes (Fig. 3). In addition, $\mathrm{PG}$ activity in protein extracts from fruit tissue was the same in both genotypes (Arancibia and Motsenbocker, 2003) suggesting that there may be another factor affecting $P G$ activity.

The association between the DPE and the fruit detachment force found in this study suggests that the DPE has an effect on PG-mediated pectin degradation and hence on the ease of fruit separation in tabasco pepper. Pectin methyl-esterase (PME) activity could enhance PG activity by increasing the amount of substrate available as reported by in vitro studies (Koch and Nevins 1989; Pressey and Avants, 1982; Wakabayashi et al., 2003). During growth and development, pectin is synthesized fully esterified so it can be transported in solution and the process of de-esterification occurs at the destination site by PME as required (Jarvis, 1984). In early ripening tomato, however, PME activity extracted from disrupted fruit tissue increased (Harriman et al., 1991; Pressey and Avants, 1982), but DPE either decreased dramatically (Koch and Nevins, 1989), decreased slightly (Tieman et al., 1992), or remained the same (Koch and Nevins, 1990). Similarly, the DPE in cell wall extracted from ripe fruit detachment zones was different between the EZ and HP tabasco pepper genotypes (Fig. 4). These results may be explained by differential expression of specific PME isozymes during ripening (Pressey and Avants, 
1972). In the EZ tabasco genotype, pectin de-esterification in vivo by a ripening specific PME activity may have increased the proportion of polygalacturonic acid susceptible to PG depolymerization. In contrast, pectin degradation in HP peppers appears to be limited to those de-esterified areas that originated during fruit growth and therefore released larger esterified uronide polymers (Wakabayashi et al., 2003).

Pectin ultra-degradation facilitates pepper harvest, but may affect certain characteristics of the processed product. Pepper cultivars with the deciduous fruit trait have been selected specifically for mechanical harvest (Bosland and Iglesias, 1992; Davis, 1980; Motsenbocker, 1996). In fact, hand harvest of EZ tabasco fruit was more efficient and mechanical harvest yield was three times higher than HP fruit (Davis, 1980). Differences in the processed product between pepper cultivars with the deciduous and nondeciduous fruit trait, however, were not indicated. In processed tomato, texture depends directly on pectin integrity which is maintained during the process (Brummell and Labavitch, 1997; Hurtado et al., 2002). Textural characteristics of pepper products, however, may not be the same as tomato products since pepper sauces are salted and fermented. Although pectin is degraded during fermentation of pepper mash (P.W. Wilson, unpublished data), the effect of ultra-degraded pectin on fermentation and on the final product has not been addressed. Dried pepper powder may also be affected by the level of pectin degradation. Disintegrated fruit tissue may be easier to dehydrate and the powder may dissolve better when added to other food products than cultivars without this trait. Therefore, the effect of pectin degradation on processed pepper products needs to be evaluated.

\section{Literature Cited}

Ahmed, A.E. and J.M. Labavitch. 1977. A simplified method for accurate determination of cell wall uronide content. J. Food Biochem. $1: 361-365$.

Arancibia, R.A. and C.E. Motsenbocker. 2003. Pectin methyl-esterase activity in vivo during fruit ripening and the deciduous character of tabasco pepper fruit. HortScience 38:838. (Abstr.)

Blumenkrantz, N. and G. Asboe-Hansen. 1973. New method for quantitative determination of uronic acids. Anal. Biochem. 54:484-489.

Bosland, P.W. and J. Iglesias. 1992. 'NuMex Bailey Piquin' chile pepper. HortScience 27:941-942.

Brummell, D.A. and M.H. Harpster. 2001. Cell wall metabolism in fruit softening and quality and its manipulation in transgenic plants. Plant Mol. Biol. 47:311-340.

Brummell, D.A. and J.M. Labavitch. 1997. Effect of antisense suppression of endopolygalacturonase activity on polyuronide molecular weight in ripening tomato fruit and in fruit homogenates. Plant Physiol. 115:717-725.

Davis, G.J. 1980. Differences between tabasco pepper selections in amounts of force required to separate fruit from the plant. MS Thesis, Dept. of Horticulture, Louisiana State Univ., Baton Rouge. Microfilm 886 reel 1176.

DellaPenna, D., C.C. Lashbrook, K. Toenjes, J.J. Giovannoni, R.L. Fisher, and A.B. Bennett. 1990. Polygalacturonase isozymes and pectin depolymerization in transgenic rin tomato fruit. Plant Physiol. 94:1882-1886.

Gersch, K.P., C.E. Motsenbocker, and G.A. Lang. 1998. Anatomical description of the fruit-receptacle detachment area in cayenne pepper. J. Amer. Soc. Hort. Sci. 123:550-555.

Gross, K.C. and S.J. Wallner. 1979. Degradation of cell wall polysac- charides during tomato fruit ripening. Plant Physiol. 63:117-120.

Harriman, R.W., D.M. Tieman, and A.K. Handa. 1991. Molecular cloning of tomato pectin methylesterase gene and its expression in Rutgers, ripening inhibitor, nonripening, and never ripe tomato fruits. Plant Physiol. 97:80-87.

Huber, D.J. 1983. Polyuronide degradation and hemicellulose modifications in ripening tomato fruit. J. Amer. Soc. Hort. Sci. 108:405-409.

Huber, D.J. and E.M. O'Donoghue. 1993. Polyuronides in avocado (Persea americana) and tomato (Lycopersicon esculentum) fruits exhibit markedly different patterns of molecular weight downshifts during ripening. Plant Physiol. 102:473-480.

Hurtado, M.C., L.C. Greve, and J.M. Labavitch. 2002. Changes in cell wall pectins accompanying tomato (Lycopersicon esculentum Mill.) paste manufacture. J. Agr. Food Chem. 50:273-278.

Jarvis, M.C. 1984. Structure and properties of pectin gels in plant cell walls. Plant, Cell and Environ. 7:153-164.

Koch, J.L. and D.J. Nevins. 1989. Tomato fruit cell wall. I. Use of purified tomato polygalacturonase and pectinmethylesterase to identify developmental changes in pectins. Plant Physiol. 91:816-822.

Koch, J.L. and D.J. Nevins. 1990. The tomato fruit cell wall. II. Polyuronide metabolism in a nonsoftening tomato mutant. Plant Physiol. 92:642-647.

Lester, D.R., W.B. Sherman, and B.J. Atwell. 1996. Endopolygalacturonase and the Melting flesh $(M)$ locus in peach. J. Amer. Soc. Hort. Sci. 121:231-235.

Motsenbocker, C.E. 1996. Detachment force and fruit characteristics of tabasco pepper at several stages of development. HortScience 31:1231-1233.

Pressey, R. and J.K. Avants. 1972. Multiple forms of pectinesterase in tomatoes. Phytochemistry 11:3139-3142.

Pressey, R. and J.K. Avants. 1982. Solubilization of cell walls by tomato polygalacturonases: effects of pectinesterases. J. Food Biochem. 6:57-72.

Rao, G.U. and I. Paran. 2003. Polygalacturonase: a candidate gene for the soft flesh and deciduous fruit mutation in Capsicum. Plant Mol. Biol. 51:135-141.

Rick, C.M. and A.C. Sawant. 1955. Factor interactions affecting the phenotypic expression of the jointless character in tomatoes. Proc. Amer. Soc. Hort. Sc. 66:354-360.

Sethu, K.M.P, T.N. Prabha, and R.N. Tharanathan. 1996. Post-harvest biochemical changes associated with the softening phenomenon in Capsicum annuum fruits. Phytochemistry 42:961-966

Smith, P.G. 1951. Deciduous ripe fruit character in peppers. Proc. Amer. Soc. Hort. Sci. 57:343-344

Sundberg, M., C.E. Motsenbocker, and L. Huang. 2003. Anatomy of fruit detachment in tabasco pepper (Capsicum frutescens) Solanaceae. J. Torrey Botanical Soc. 130:231-237.

Tieman, D.M., R.W. Harriman, G. Ramamohan, and A.K. Handa. 1992. An antisense pectin methylesterase gene alters pectin chemistry and soluble solids in tomato fruit. The Plant Cell 4:667-679.

Wakabayashi, K., T. Hoson, and D.J. Huber. 2003. Methyl de-esterification as a major factor regulating the extent of pectin depolymerization during fruit ripening: A comparison of the action of avocado (Persea americana) and tomato (Lycopersicon esculentum) polygalacturonases. J. Plant Physiol. 160:667-673.

Watson, C.F., L. Zheng, and D. DellaPenna. 1994. Reduction of tomato polygalacturonase $\beta$ subunit expression affects pectin solubilization and degradation during fruit ripening. The Plant Cell 6:1623-1634.

Wood, P.J. and I.R. Siddiqui. 1971. Determination of methanol and its application to measurement of pectin ester content and pectin methyl esterase activity. Anal. Biochem. 39:418-428.

Zanchin, C. Bonghi, G. Casadoro, A. Ramina, and N. Rascio. 1993. Abscission in leaf and fruit explants of Prunus persica (L.) Batsch. New Phytol. 123:555-565. 